\title{
Perancangan Model Stacker Crane Flexible Manufacturing System untuk Pembelajaran di Institusi Pendidikan
}

\author{
Ari Setiawan ${ }^{1}$, Nehemia Karo Sekali ${ }^{2}$ \\ 1, 2)Program Studi Teknik Industri, Institut Teknologi Harapan Bangsa \\ Jalan Dipatiukur No. 80 - 84, Bandung, Indonesia 40132 \\ Email: ari_setiawan@ithb.ac.id, ti-16027@students.ithb.ac.id
}

\begin{abstract}
Flexible Manufacturing System (FMS) is one of the modern production systems that support the implementation of Industry 4.0. An educational institution plans to build an FMS model for learning the modern production systems. The FMS is a manufacturing system consisting of a set of automatic workstations connected to a material handling system where all activities are controlled by a computer system. The material handling system consists of a material storage system and a transportation system, one example of a transportation system is the stacker crane. In this research, the stacker crane model has been built which consists of three main components, which are the bottom frame, the mast, and the carriage. This component is equipped with stepper motors, leadscrews that are controlled by the micro controller and an application on Android. The stacker crane model is tested to retrieve and deliver the stereofoam material model to the destination which is controlled by the user using an application on Android. The characteristics of the stacker crane model can move the workpiece with a maximum error of $2 \mathrm{~mm}$ in the positive $x$-axis direction, $2 \mathrm{~mm}$ in the negative $x$-axis movement, up to $2 \mathrm{~mm}$ positive $y$ axis, downward at negative $y$-axis direction $2 \mathrm{~mm}$.
\end{abstract}

Keywords: Flexible Manufacturing System (FMS), stacker crane, microcontroller

\begin{abstract}
Abstrak
Flexible Manufacturing System (FMS) dimanfaatkan sebagai salah satu peralatan yang mendukung implementasi Industri 4.0. Sebuah institusi pendidikan berencana membangun model FMS untuk pembelajaran sistem produksi modern. FMS merupakan sistem manufaktur yang terdiri dari sekumpulan stasiun kerja otomatis yang terkoneksi dengan sistem material handling yang mana semua aktivitasnya dikendalikan oleh sistem komputer. Sistem material handling terdiri dari sistem penyimpanan material dan sistem transportasi. Salah satu contoh sistem transportasi adalah stacker crane. Pada penelitian ini telah dibangun sebuah model stacker crane yang terdiri dari tiga komponen utama yaitu bottom frame, mast, dan carriage. Komponen ini dilengkapi dengan stepper motor, leadscrew yang dikendalikan oleh mikrokontroler dan aplikasi pada android. Model stacker crane diuji coba untuk mengambil dan mengantarkan model material berupa styrofoam ke tempat tujuan yang dikendalikan oleh user menggunakan aplikasi pada android. Karakteristik model stacker crane yang dibangun mempunyai kemampuan memindahkan barang dengan kesalahan maksimum sebesar $2 \mathrm{~mm}$ ke arah sumbu-x positif, $2 \mathrm{~mm}$ pada gerakan ke arah sumbu-x negatif, ke atas pada sumbu-y positif $2 \mathrm{~mm}$, ke bawah pada arah sumbu-y negatif $2 \mathrm{~mm}$.
\end{abstract}

Kata kunci: Flexible Manufacturing System (FMS), stacker crane, mikrokontroler

\section{Pendahuluan}

Revolusi Industri 4.0 telah mengubah sistem produksi, dari sistem produksi yang dioperasikan secara mekanik menjadi sistem yang dikendalikan dengan teknologi mekatronik dan memanfaatkan jaringan internet. Salah satu fasilitas produksi yang banyak dimanfaatkan pada era industri 4.0 adalah 
Flexible Manufacturing System (FMS). Menurut Setiawan et al. (2019) FMS merupakan sistem manufaktur yang terdiri dari sekumpulan stasiun kerja otomatis yang terkoneksi dengan sistem material handling dimana semua aktivitasnya dikendalikan oleh sistem komputer. Stasiun kerja otomatis pada FMS terdiri dari mesin-mesin Computerized Numerical Control (CNC). Sistem material handling terdiri dari sistem penyimpanan material dan sistem transportasi. Sistem penyimpanan material, dapat berupa rak yang tersusun atas sejumlah baris dan kolom yang dinamakan Pallet Stocker. Sistem transportasi berfungsi untuk mengantarkan material di dalam FMS, misalnya Automated Guided Vehicle System (AGV) dan stacker crane. Konstruksi AGV memanfaatkan beberapa roda pada rangka seperti halnya sebuah mobil truk. Konstruksi stacker crane menggunakan komponen guideways, seperti fungsi rel pada sebuah pintu geser. Baik pada AGV maupun stacker crane, terdapat komponen robot yang dapat mengambil dan meletakkan material atau benda kerja. Pada FMS, material atau benda kerja di-clamp pada sebuah fixture, yang mana fixture ini berada di permukaan pallet yang ukurannya sudah standar. Dengan demikian, pallet akan dipindah-pindahkan oleh sistem transportasi di dalam FMS. Sistem operasi pada FMS, dikendalikan oleh komputer yang terpusat, sehingga FMS dapat beroperasi secara otomatis tanpa harus dijaga oleh operator. FMS dan komponennya ditunjukkan pada Gambar 1.

Sebuah institusi pendidikan berencana membangun model FMS yang akan digunakan untuk pembelajaran pada mata kuliah sistem produksi modern yang berkaitan dengan revolusi industri 4.0. Untuk itu beberapa penelitian telah diupayakan dalam rangka pembangunan model FMS. Diantaranya adalah Hilmanto et al. (2018) telah mengembangkan model penjadwalan FMS dengan memperhatikan sistem penanganan material berupa stacker crane dan pallet stocker. Elroy \& Setiawan (2019) telah membangun sebuah rancangan sistem Shop Floor Control untuk pengendalian FMS, yang sebelumnya Utomo et al. (2018) mengembangkan sistem Radio Frequency Identification (RFID) untuk mengambil data benda kerja pada FMS. Febrian \& Setiawan (2019) mengembangkan model mesin CNC, khususnya pada komponen Automatic Pallet Changer (APC).

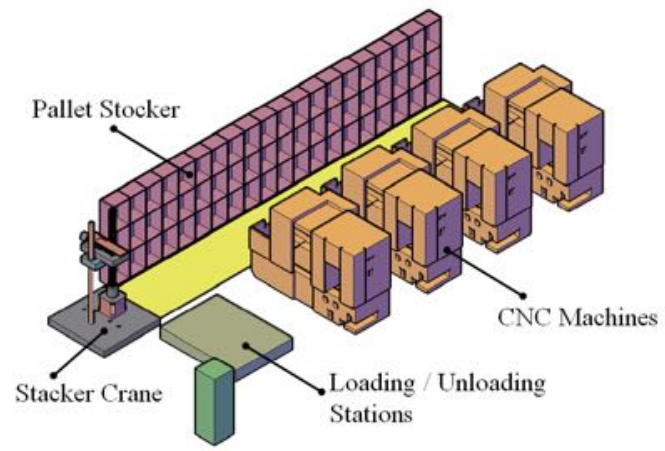

Gambar 1. FMS dan komponennya Sumber: Setiawan et al. (2019)

Untuk sistem transportasi dan penanganan material, Bawono \& Setiawan (2019) merancang model AGV untuk FMS. Model AGV sangat baik sebagai sistem transportasi antar FMS. Model AGV yang dikembangkan Bawono berupa integrasi dari robot line follower dan robotic arm yang ditunjukkan pada Gambar 2. Robot line follower merupakan model kendaraan angkut tiga roda yang menggunakan dua buah motor DC pada masing-masing dua roda penggerak dan sebuah roda yang independen. Robotic arm merupakan lengan robot yang digunakan untuk mengambil dan meletakkan benda kerja.

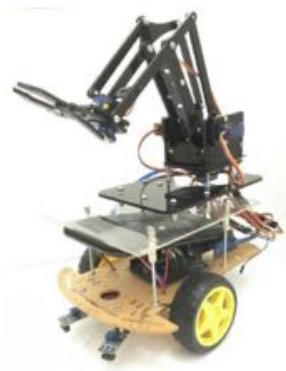

Gambar 2. AGV Rancangan

Sumber: Bawono \& Setiawan (2019)

Model AGV ini mempunyai kelemahan dimana masih menggunakan dua buah microcontroller serta pergerakan AGV yang tidak dapat mundur atau hanya bisa berjalan satu arah memutar yang cukup memakan waktu. Untuk memperbaiki kelemahan ini, akan dikembangkan sistem transportasi lain, berupa sebuah stacker crane dengan konsep yang berbeda dengan AGV.

Penelitian lain yang berkaitan dan mendukung pengembangan stacker crane yang akan dibangun adalah penelitian Andika (2013). Andika mengembangkan alat pengontrol robot 
berbasis arduino menggunakan android, dimana penghubung komunikasi antara robot arduino dengan android menggunakan modul bluetooth. Hadisantoso \& Tamsir (2018) meneliti sebuah rancangan menggunakan arduino dan web untuk sistem penyimpanan dan pengambilan barang agar pengambilan dan penyimpanan barang dapat dilakukan secara otomatis. Input pada penelitian Hadisantoso \& Tamsir (2018) menggunakan barcode scanner. Dengan demikian penelitian yang diajukan adalah membangun sebuah model stacker crane untuk mengambil dan menyimpan barang yang diteliti oleh Bawono, khususnya penelitian Hadisantoso akan tetapi untuk input-nya akan menggunakan modul bluetooth yang diteliti oleh Andika. Untuk melengkapi penelitian, diperlukan kajian dari penelitian lain yaitu Fatoni \& Rendra (2014) yang merancang sistem kendali menggunakan handphone arduino berbasis arduino. Selain itu Pratama (2017) meneliti kontroler lengan robot menggunakan motor servo dan motor stepper dengan masukan 3-axis.

\section{Metodologi}

Sitepu \& Setiawan (2016) menjelaskan bahwa Flexible Manufacturing System (FMS) adalah kumpulan dari mesin yang saling terhubung dengan sistem transportasi yang membawa benda kerja dalam bentuk pallet sehingga proses benda kerja dengan mesin dapat berjalan dengan cepat, akurat, dan otomatis. Pada FMS terdapat sebuah komputer, dimana komputer tersebut adalah pusat pengendali baik mesin maupun sistem transportasinya, seperti dijelaskan pada Gambar 1.

Stacker crane adalah peralatan yang digunakan untuk mengambil, mengantarkan dan meletakkan barang pada rak bersusun (pallet stocker). Alat otomatis ini dibangun agar dapat mempersingkat waktu dalam proses penyimpanan dan pengambilan barang pada rak bersusun. Selain itu alat ini dapat beroperasi tanpa harus dikendalikan oleh operator (Andika, 2013). Konstruksi stacker crane terdiri dari bottom frame yang merupakan chassis dari stacker crane agar dapat bergerak ke arah horizontal atau dalam arah sumbu- $x$. Kemudian mast yaitu komponen tegak yang dapat bergerak ke arah vertikal atau arah sumbu-y. Sedangkan komponen berikutnya adalah carriage yaitu komponen yang mengambil dan meletakkan barang pada tempatnya. Gerakan carriage disebut dengan arah gerakan sumbu-z.

\section{Perancangan Model}

Konstruksi FMS yang akan dikembangkan diambil dari perguruan tinggi yang akan menggunakan Model FMS, terdiri dari pallet, stacker crane, mesin CNC, dan komputer. Data ukuran dan dimensi FMS tersebut diperoleh dari penelitian yang sudah dilakukan oleh Setiawan et al. (2019), serta Sitepu \& Setiawan (2018). Adapun gambaran model konstruksi FMS yang akan dibangun dapat dilihat pada Gambar 3. Pada model FMS, hanya terdiri dari sebuah mesin CNC dan sebuah load/unload station dan pallet stocker yang terdiri dari tiga baris dan tiga kolom.

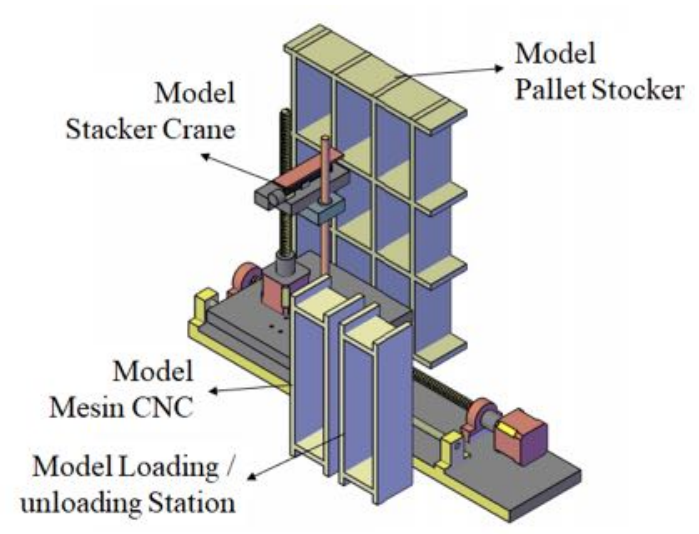

Gambar 3. Penyederhanaan model konstruksi FMS pada penelitian ini.

\section{Perancangan Model Stacker Crane}

Fokus dari penelitian ini adalah perancangan model stacker crane yang dimulai dengan mencermati komponen-komponen model yang secara umum terdiri dari bottom frame, mast, dan carriage. Gambaran konstruksi yang akan dibangun, digambar menggunakan aplikasi gambar teknik seperti ditunjukkan pada Gambar 4.

\section{Perancangan Bottom Frame}

Bottom frame terdiri dari komponen hardware mekanik, hardware elektronik serta software. Untuk bagian mekanik, pada bagian bottom frame terdapat stepper motor yang memutar lead screw rod searah jarum jam maupun berlawanan, sehingga nut-follower dapat bergerak dari kanan ke kiri pada sumbu$x$. Untuk menyeimbangkan gerakan lead screw, 
digunakan guide way. Panjang lead screw maupun panjang guide way yang digunakan adalah $400 \mathrm{~mm}$. Motor stepper ini dikontrol oleh mikrokontroler. Ukuran dudukan bottom frame yang terbuat dari kayu adalah $500 \mathrm{~mm}$ panjang dan $160 \mathrm{~mm}$ lebar. Berikut, pada Gambar 5, konstruksi bottom frame yang terdiri dari stepper motor, lead screw rod dan guideways.

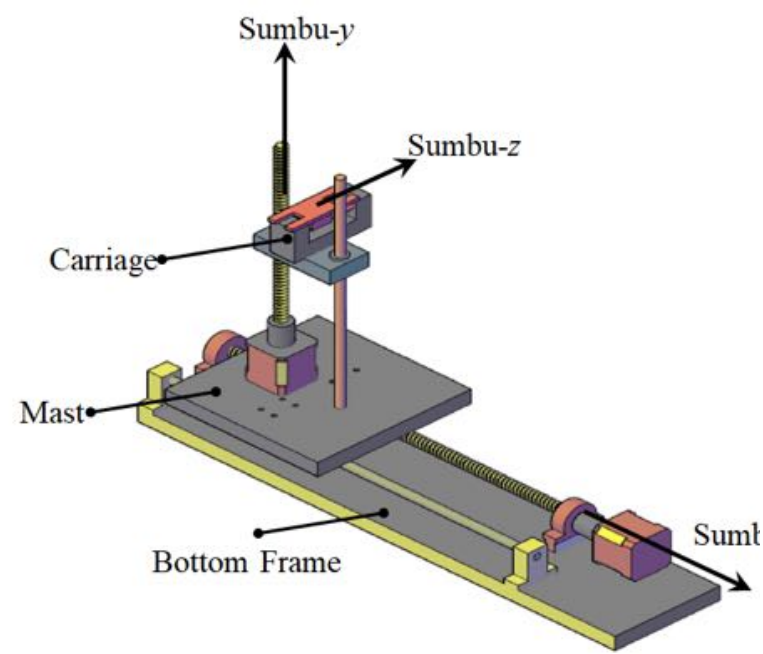

Gambar 4. Bagian-bagian model stacker crane

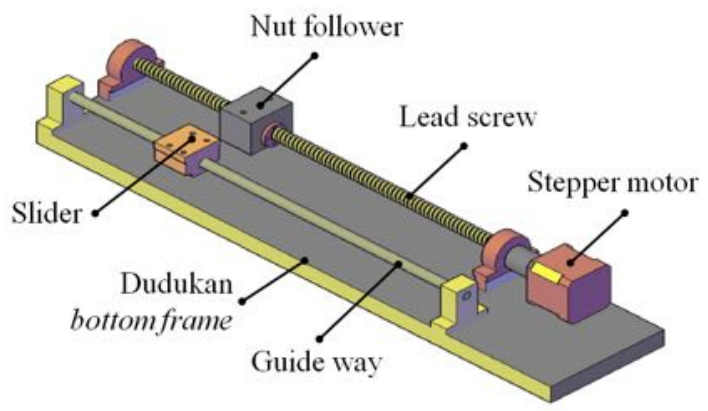

Gambar 5. Komponen bottom frame

Rancangan elektronika bottom frame terdiri dari tiga bagian utama yaitu input yang berasal dari aplikasi android. Input akan diterima oleh modul HC-05 melalui fasilitas bluetooth dan diteruskan ke mikrokontroler. Output proses ini adalah stepper motor yang akan berputar sesuai input yang diberikan oleh user. Putaran stepper motor akan menggerakkan lead screw searah atau berlawanan arah jarum jam. Dengan demikian nut-follower akan menggerakkan mast bergerak ke kiri atau ke kanan pada sumbu- $x$. Diagram input output bottom frame pada stacker crane ditunjukkan pada Gambar 6.

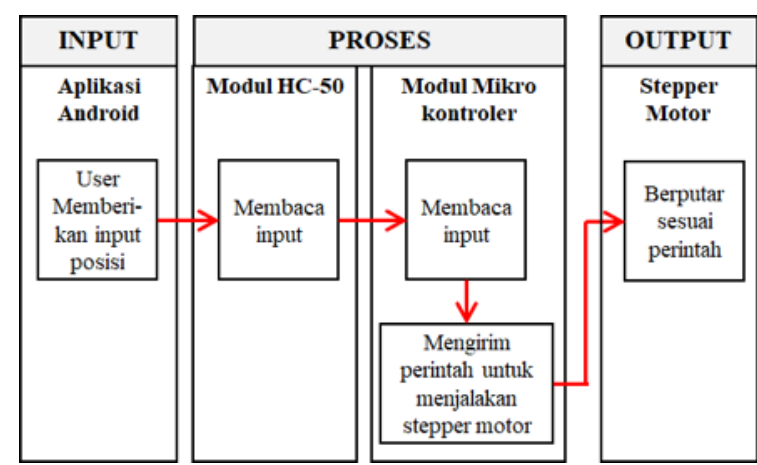

Gambar 6. Diagram input output pada rangkaian modul

Rangkaian elektronik bottom frame membutuhkan beberapa komponen, diantaranya adalah stepper motor sebagai komponen utama untuk menggerakkan lead screw. Jenis stepper motor yang digunakan pada penelitian ini adalah stepper nema-17. Untuk dapat mengendalikan stepper motor agar dapat berputar searah atau berlawanan arah jarum jam, diperlukan motor driver. Pada penelitian ini digunakan model L298N sebagai motor driver. Modul L298N dihubungkan dengan mikrokontroler yang mana pada penelitian ini menggunakan Arduino-Uno. Input untuk mikrokontroler diberikan oleh modul $\mathrm{HC}$ 05 yang merupakan modul yang dapat berkomunikasi secara nirkabel menggunakan bluetooth dengan aplikasi android yang bernama "Serial Bluetooth Terminal". Berikut pada Gambar 7, adalah rangkaian untuk bottom frame. Rangkaian ini serupa untuk rangkaian elektrik mast dan rangkaian elektrik carriage. Tetapi pada carriage, stepper motor Nema diganti dengan stepper motor DVD.

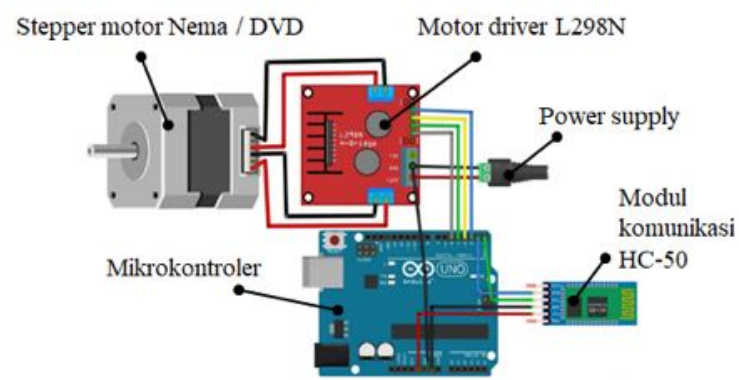

Gambar 7. Rangkaian elektrik bottom frame

\section{Perancangan Mast}

Mast terdiri dari komponen hardware mekanik dan elektronik serta software. Mast dapat bergerak dari atas ke bawah pada sumbu-y. Pergerakan ini dapat terjadi karena motor stepper memutar lead screw searah 
jarum jam maupun berlawanan. Untuk menyeimbangkan gerakan lead screw, digunakan guide way. Panjang lead screw yang digunakan adalah $200 \mathrm{~mm}$, sedangkan untuk guide way yang digunakan adalah $250 \mathrm{~mm}$. Motor stepper ini dikontrol oleh mikrokontroler. Ukuran dudukan mast yang terbuat dari kayu dengan panjang dan lebar $160 \mathrm{~mm}$ dan 160 $\mathrm{mm}$. Berikut pada Gambar 8 ditunjukkan konstruksi mast yang terdiri dari stepper motor, lead screw rod dan guideways.

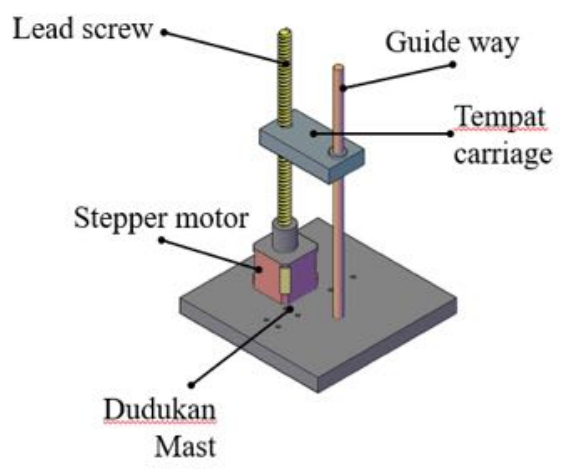

Gambar 8. Komponen mast

Rancangan elektronika mast terdiri dari tiga bagian utama yaitu input yang berasal dari aplikasi android. Input akan diterima oleh modul HC-05 melalui fasilitas bluetooth dan diteruskan ke mikrokontroler. Aplikasi tersebut dapat diunduh melalui play store. Output proses ini adalah stepper motor yang akan berputar sesuai input yang diberikan oleh user. Putaran stepper motor akan menggerakan lead screw untuk carriage baik dari atas ke bawah maupun sebaliknya pada sumbu-y. Proses input-output mast serupa dengan bottom frame pada Gambar 6.

Rangkaian elektronik mast membutuhkan beberapa komponen, diantaranya adalah stepper motor sebagai komponen utama untuk menggerakkan lead screw. Untuk memudahkan perancangan, jenis stepper motor yang digunakan pada penelitian ini sama dengan jenis untuk komponen bottom frame, yaitu stepper nema-17. Untuk dapat mengendalikan stepper motor agar dapat berputar searah atau berlawanan arah jarum jam, diperlukan motor driver yaitu Modul L298N. Modul L298N dihubungkan dengan mikrokontroler yang mana pada penelitian ini menggunakan Arduino-Uno. Input untuk mikrokontroler diberikan oleh modul HC-05 yang merupakan modul yang dapat berkomunikasi secara nirkabel menggunakan bluetooth dengan aplikasi Serial Bluetooth Terminal.

\section{Perancangan Carriage}

Carriage merupakan komponen stacker crane yang berfungsi untuk mengambil dan meletakkan pallet dari rak. Komponen carriage terdiri dari hardware mekanik, hardware elektronik dan software. Gerakan carriage hanya pergerakan maju dan mundur pada satu jarak saja pada sumbu-z. Komponen stepper motor yang digunakan pada carriage berbeda dengan stepper motor untuk bottom frame dan mast. Komponen yang digunakan pada carriage adalah stepper motor DVD sudah bersatu dengan leadscrew, yang mempunyai panjang $90 \mathrm{~mm}$. Untuk dudukan pengambil pallet, digunakan kardus yang mempunyai bobot ringan. Stepper motor DVD diletakkan pada sebuah dudukan dari kayu dengan panjang $100 \mathrm{~mm}$ dan lebar $45 \mathrm{~mm}$, yang ditunjukkan pada Gambar 9.

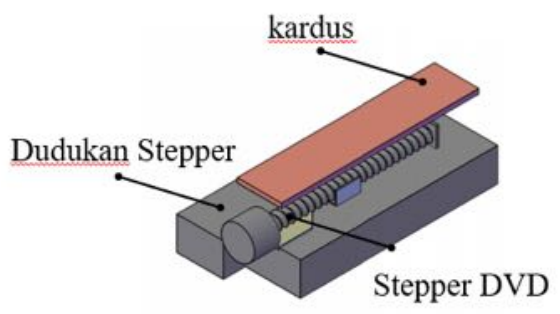

Gambar 9. Komponen carriage

Rancangan elektronika carriage terdiri dari tiga bagian utama yaitu input yang berasal dari aplikasi android. Input akan diterima oleh modul HC-05 melalui fasilitas bluetooth dan diteruskan ke mikrokontroler. Output proses ini adalah stepper DVD yang akan berputar sesuai input yang diberikan oleh user. Putaran stepper DVD akan bergerak maju atau mundur pada sumbuz. Rangkaian elektronik carriage membutuhkan beberapa komponen, diantaranya adalah stepper DVD yang ditunjukkan pada Gambar 7. Untuk dapat mengendalikan stepper DVD agar dapat berputar searah atau berlawanan arah jarum jam, diperlukan motor driver. Pada penelitian ini digunakan model L298N sebagai motor driver.

\section{Pembuatan Model Stacker Crane}

Setelah perancangan bagian-bagian dari stacker crane selesai dilakukan, maka tahap selanjutnya adalah membuat hardware dan 
mengintegrasikan semua bagian menjadi sebuah model stacker crane. Pertama adalah dengan menggabungkan alas stacker crane dengan mast, dimana dudukan mast akan disatukan dengan nut-follower pada bottom frame dengan menggunakan sekrup. Kemudian menggabungkan dengan carriage, dimana mast yang sudah memiliki dudukan untuk alat pengambil atau penyimpan barang akan digabungkan.

Untuk mengoperasikan hardware stacker crane diperlukan modul software untuk menggerakkan motor. Logika untuk menggerakkan stacker crane dimulai dengan menggerakkan bottom frame pada sumbu- $x$, sesuai input sehingga berhenti pada lokasi stasiun kerja. Kemudian mast bergerak pada sumbu-y hingga lokasi rak yang dikehendaki. Selanjutnya carriage akan bergerak maju pada sumbu-z untuk mengambil pallet pada rak. Setelah pallet diambil dari rak, kemudian carriage bergerak mundur dari sumbu-z. Selanjutnya mast akan bergerak turun ke bawah pada sumbu-y hingga di posisi nol sumbu-y. Kemudian carriage bergerak ke tempat tujuan stasiun kerja selanjutnya pada sumbu-x. Logika operasi stacker crane ini disusun menjadi tiga diagram alir sebagai berikut. Diagram alir pertama adalah diagram alir untuk menggerakkan bottom frame dan mast pada lokasi yang dituju (Gambar 10).

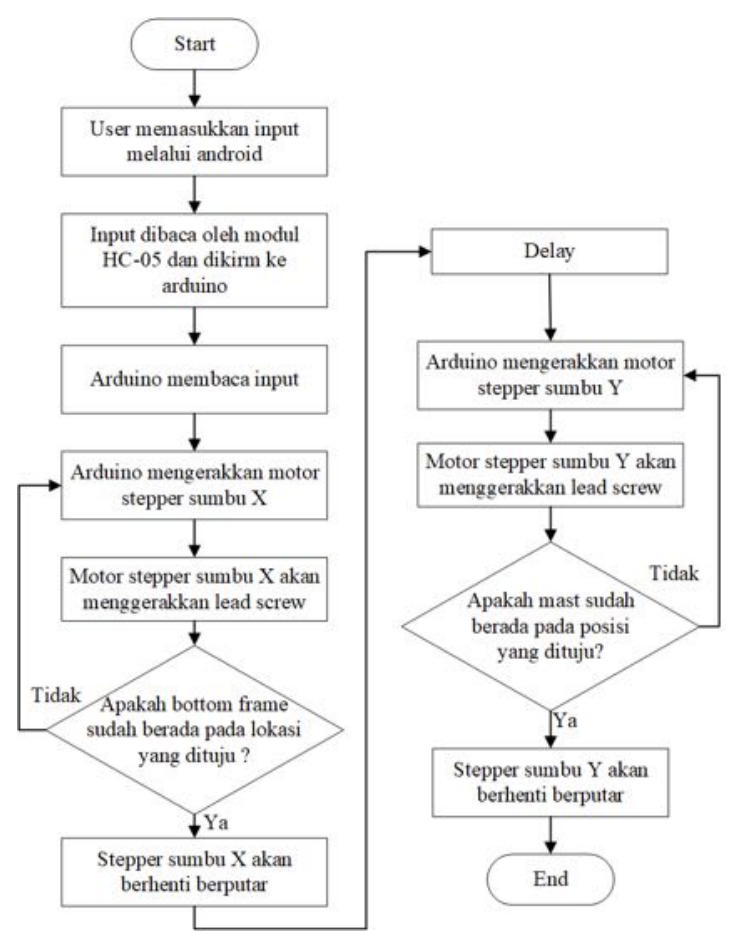

Gambar 10. Diagram alir operasi bottom frame dan mast ke lokasi yang dituju
Diagram alir yang kedua adalah diagram alir untuk mengangkat benda kerja dan menyiapkan untuk diantar ke lokasi yang akan dituju. Dengan demikian benda kerja masih terdapat pada carriage. Kemudian diagram alir yang ketiga adalah diagram alir untuk menurunkan benda kerja yang sudah ada pada carriage di lokasi yang dituju (Gambar 11).
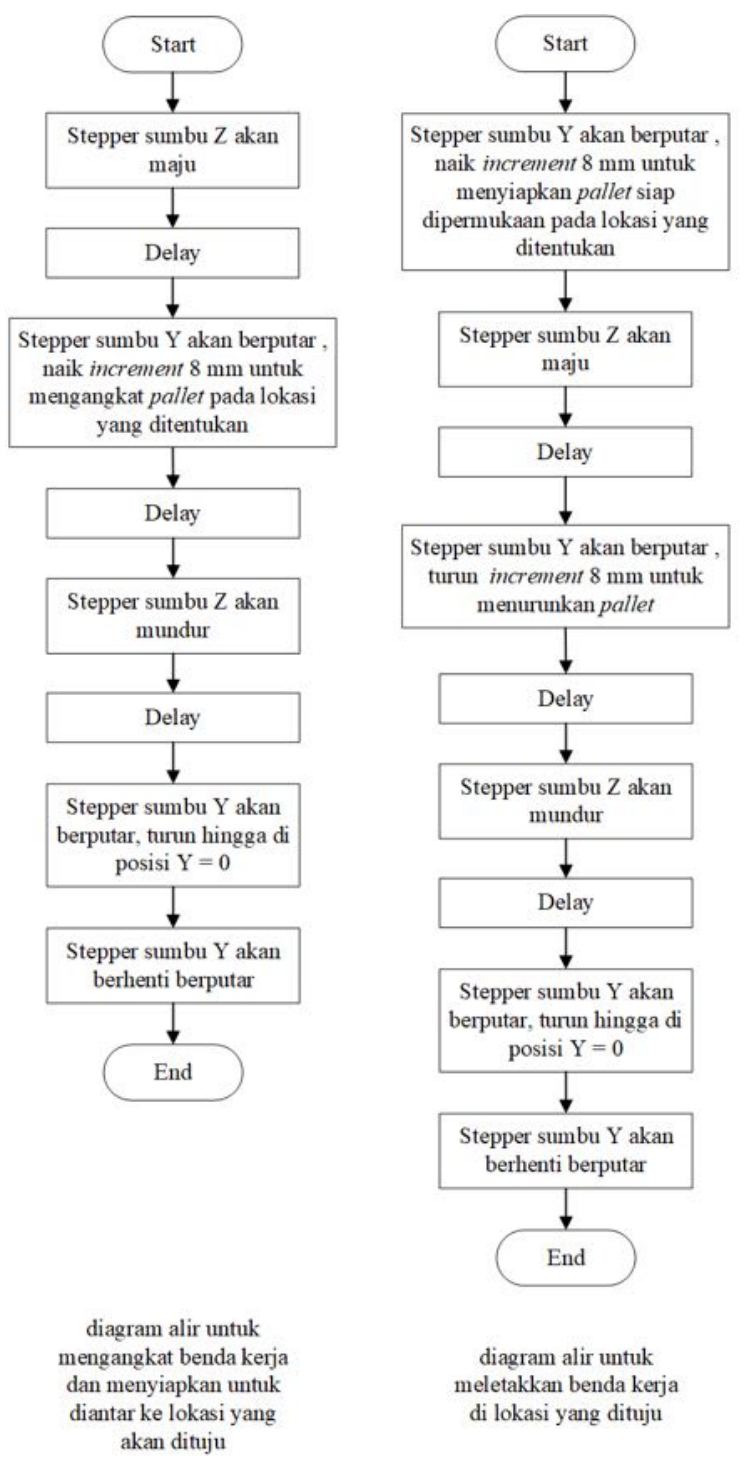

Gambar 11. Diagram alir mengangkat dan meletakkan benda kerja pada lokasi yang dituju

\section{Pengujian dan Analisis}

Setelah perancangan model stacker crane selesai dilakukan, maka pada tahap ini akan dilakukan pengujian. Pada tahap pengujian dan analisis akan dilakukan dua pengujian yaitu pengujian setiap bagian pada masing-masing komponen stacker crane (Bottom frame, mast dan carriage) dan pengujian model stacker crane. 


\section{Pengujian Bottom Frame}

Pengujian ini akan dilakukan untuk mengetahui apakah Bottom frame bergerak sesuai perintah yang diberikan melalui aplikasi Serial Bluetooth Terminal android. Sebelumnya telah dilakukan proses kalibrasi untuk memastikan bahwa perintah melalui androids dapat menggerakkan bottom frame ke tempat yang dituju. Set-up pengujian dilakukan dengan menggerakkan bottom frame dari satu lokasi ke tempat tujuan. Kemudian diuji apakah bottom frame berhenti melebihi atau berhenti sebelum posisi yang ditentukan dan mengukurnya menggunakan alat ukur dengan ketelitian \pm $0,5 \mathrm{~mm}$. Susunan bottom frame dan lokasi berhenti ditunjukkan pada gambar pandangan atas lokasi stasiun kerja, dijelaskan Gambar 12. Kesalahan posisi selama tujuh kali pengujian yang dilakukan untuk memindahkan dari sebuah posisi ke posisi lain ditunjukkan pada Tabel 1.

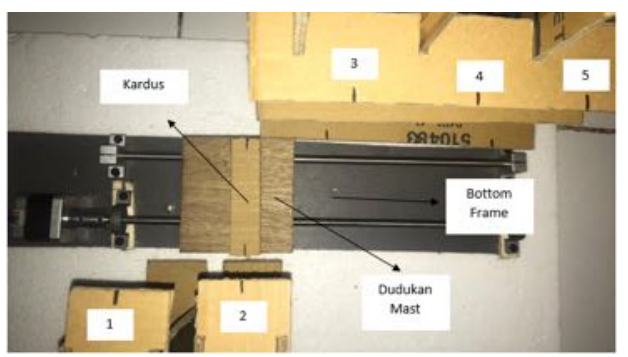

Gambar 12. Setup pengujian bottom frame, dilihat dari pandangan atas

\section{Pengujian Mast}

Mast yang digunakan pada penelitian ini akan diuji apakah mast bergerak dalam arah ke atas maupun ke bawah pada sumbu-y sesuai perintah yang diberikan melalui android dan apakah dapat berhenti tepat pada lantai tertentu. Susunan konstruksi pengujian disajikan dengan padangan depan stacker crane yang terdiri dari tiga tingkat, ditunjukkan pada Gambar 13. Pengujian dilakukan sebanyak tujuh kali dan eror selama pengujian ditunjukkan pada Tabel 2.

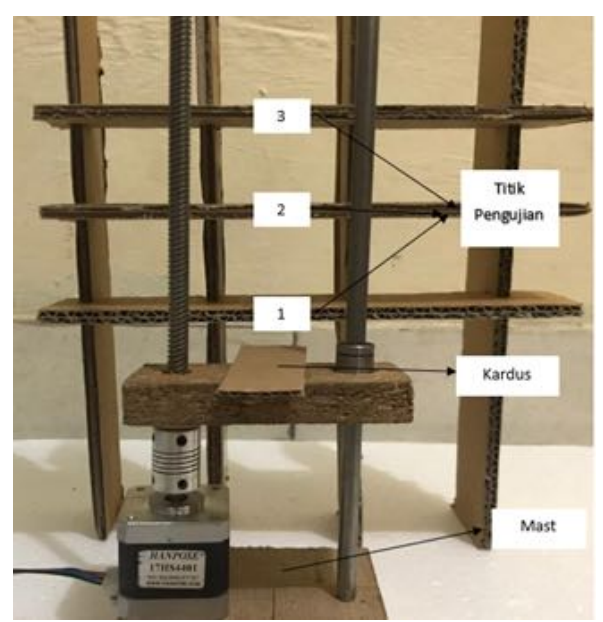

Gambar 13. Setup pengujian mast, dilihat dari pandangan depan

Tabel 1. Eror pengujian bottom frame

\begin{tabular}{|c|c|c|c|c|c|c|c|c|c|}
\hline \multirow{3}{*}{$\begin{array}{c}\text { No. } \\
\text { Pengujian }\end{array}$} & \multirow{3}{*}{ Posisi Asal } & \multirow{3}{*}{$\begin{array}{l}\text { Posisi } \\
\text { Tujuan }\end{array}$} & \multicolumn{7}{|c|}{ Eror dalam tujuh kali percobaan $(\mathrm{mm})$, ketelitian $\pm 0,5 \mathrm{~mm}$} \\
\hline & & & \multicolumn{7}{|c|}{ Percobaan ke: } \\
\hline & & & 1 & 2 & 3 & 4 & 5 & 6 & 7 \\
\hline 1 & \multirow{4}{*}{1} & 2 & 0 & -1 & -1 & 0 & 0 & 0 & -1 \\
\hline 2 & & 3 & 0 & -1 & 0 & 0 & -1 & 0 & 0 \\
\hline 3 & & 4 & 0 & 0 & -1 & 0 & 0 & 0 & 0 \\
\hline 4 & & 5 & 0 & 0 & 0 & -1 & -1 & -1 & -1 \\
\hline 5 & \multirow{4}{*}{2} & 1 & -1 & 0 & -1 & -1 & 1 & 0 & 0 \\
\hline 6 & & 3 & 0 & 0 & -1 & -1 & 0 & 0 & 2 \\
\hline 7 & & 4 & -1 & -1 & 0 & 1 & -1 & -1 & -1 \\
\hline 8 & & 5 & 0 & 0 & 0 & 1 & -1 & 0 & 0 \\
\hline 9 & \multirow{4}{*}{3} & 1 & 0 & 0 & 0 & 0 & -1 & 0 & -1 \\
\hline 10 & & 2 & 0 & -2 & 0 & 0 & 0 & 0 & 0 \\
\hline 11 & & 4 & -1 & -1 & -1 & 0 & 1 & 1 & 1 \\
\hline 12 & & 5 & -1 & -1 & -1 & -1 & 0 & 0 & 0 \\
\hline 13 & \multirow{4}{*}{4} & 1 & 1 & 2 & 2 & 0 & -2 & 0 & 0 \\
\hline 14 & & 2 & -1 & 0 & 0 & 0 & 0 & 0 & 1 \\
\hline 15 & & 3 & 0 & 0 & 0 & -1 & -1 & -1 & -1 \\
\hline 16 & & 5 & 0 & 0 & 0 & -1 & 0 & 0 & 0 \\
\hline 17 & \multirow{4}{*}{5} & 1 & -1 & -1 & 0 & 2 & 1 & 1 & 1 \\
\hline 18 & & 2 & 1 & 0 & -1 & -1 & 1 & 1 & 1 \\
\hline 19 & & 3 & -1 & -1 & -1 & 0 & 0 & 0 & 0 \\
\hline 20 & & 4 & 0 & 2 & -1 & 0 & 0 & 0 & 0 \\
\hline
\end{tabular}


Tabel 2. Eror pengujian mast

\begin{tabular}{|c|c|c|c|c|c|c|c|c|c|}
\hline \multirow{3}{*}{$\begin{array}{c}\text { No. } \\
\text { Pengujian }\end{array}$} & \multirow{3}{*}{ Posisi Asal } & \multirow{3}{*}{$\begin{array}{l}\text { Posisi } \\
\text { Tujuan }\end{array}$} & \multirow{2}{*}{\multicolumn{7}{|c|}{$\begin{array}{c}\text { Eror dalam tujuh kali percobaan }(\mathrm{mm}), \text { ketelitian } \pm 0,5 \mathrm{~mm} \\
\text { Percobaan ke: }\end{array}$}} \\
\hline & & & & & & & & & \\
\hline & & & 1 & 2 & 3 & 4 & 5 & 6 & 7 \\
\hline 1 & \multirow{2}{*}{1} & 2 & 0 & -1 & -2 & -1 & -1 & 0 & 1 \\
\hline 2 & & 3 & -1 & -2 & -1 & -2 & -2 & -1 & -1 \\
\hline 3 & \multirow{2}{*}{2} & 1 & -1 & -1 & 2 & 2 & 1 & -1 & 0 \\
\hline 4 & & 3 & 1 & -2 & 0 & -1 & 1 & 0 & -1 \\
\hline 5 & \multirow{2}{*}{3} & 1 & 0 & 0 & -1 & -1 & -1 & 2 & 1 \\
\hline 6 & & 2 & 2 & 2 & 1 & 1 & 2 & -1 & -2 \\
\hline
\end{tabular}

\section{Pengujian Carriage}

Carriage yang digunakan perlu diuji apakah dapat bergerak maju dan mundur sesuai dengan perintah yang diberikan melalui androids. Pengujian ini dilakukan sebanyak tujuh kali dan memberikan hasil yang memuaskan yang ditunjukkan pada Tabel 3 .

Tabel 3. Pengujian Carriage

\begin{tabular}{|c|c|c|}
\hline \multirow{2}{*}{ No Pengujian } & \multicolumn{2}{|c|}{ Hasil } \\
\cline { 2 - 3 } & Gerakan Maju & $\begin{array}{l}\text { Gerakan } \\
\text { Mundur }\end{array}$ \\
\hline 1 & Berhasil & Berhasil \\
\hline 2 & Berhasil & Berhasil \\
\hline 3 & Berhasil & Berhasil \\
\hline 4 & Berhasil & Berhasil \\
\hline 5 & Berhasil & Berhasil \\
\hline 6 & Berhasil & Berhasil \\
\hline 7 & Berhasil & Berhasil \\
\hline
\end{tabular}

\section{Pengujian model Stacker Crane.}

Setelah masing-masing komponen diuji dan berfungsi dengan baik, selanjutnya adalah menguji fungsi integrasi komponen stacker crane. Pengujian model stacker crane akan dilakukan untuk mengetahui apakah model stacker crane dapat mengambil dan menyimpan barang sesuai yang diperintahkan melalui android seperti halnya model FMS.

Pengujian pada model stacker crane dari loading/unloading menuju rak, dari rak menuju area peletakan benda kerja pada model mesin CNC yang berbentuk persegi (pada gambar disebut dengan kotak pengujian). Kemudian dari model mesin CNC menuju rak dan yang terakhir dari rak menuju loading/unloading. Tata letak pada pengujian stacker crane ini terdiri dari sebuah stacker crane, lokasi sebuah mesin CNC, sebuah stasiun loading/unloading, rak terdiri dari tiga tingkat dan sebuah pallet dari styrofoam, yang ditunjukkan pada Gambar 14 . Area peletakan benda kerja pada pengujian ini dibuat bentuk persegi sebagai referensi untuk menguji ketelitian. Dengan demikian akan diukur eror dalam arah sumbu- $x$ dan sumbu- $z$ pada masing-masing area peletakan.

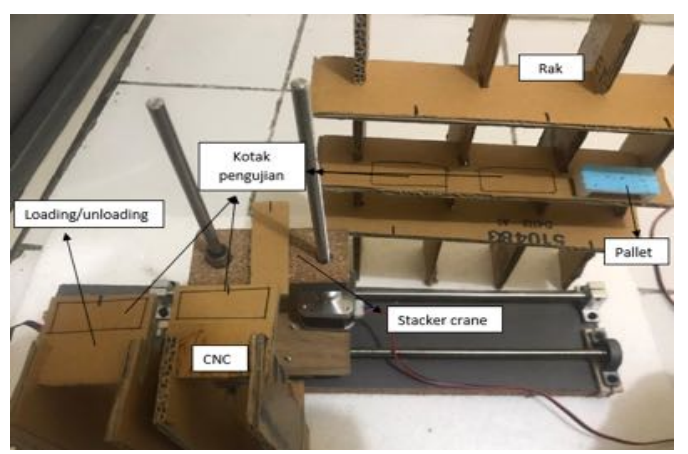

Gambar 14. Susunan pengujian model stacker crane pada model FMS

Berdasarkan tujuh kali pengujian, ditunjukkan bahwa model stacker crane dapat berfungsi meskipun belum selalu berhasil. Proses pengambilan dan pengantaran benda kerja dari loading/unloading station ke rak dapat berlangsung hanya terdapat dua kegagalan dari tujuh pada rak-2 saja. Pengambilan dan pengantaran benda kerja dari mesin CNC ke rak, hanya ada satu gagal di rak-1 dan dua gagal di rak-2. Sedangkan pengambilan dan pengantaran benda kerja dari rak ke loading/unloading station ke rak berhasil lima percobaan.

Meskipun demikian, terdapat beberapa hal yang menjadi catatan peneliti sebagai berikut ini. Dari jumlah keberhasilan untuk mengantar benda kerja, masih terdapat kesulitan mengambil benda kerja dari rak ke model mesin CNC. Hal ini ditunjukkan dari tujuh percobaan hanya ada tiga percobaan yang sukses. Sementara yang tidak sukses ditunjukkan dengan jatuhnya benda kerja pada saat proses pemindahan. Hasil pengujian model stacker crane ditunjukkan pada Tabel 4 . 
DOI: https://doi.org/10.26593/jrsi.v10i1.4258.45-54

Tabel 4. Eror pengujian Stacker Crane dalam sumbu- $x$ dan sumbu-z

\begin{tabular}{|c|c|c|c|c|c|c|c|c|c|}
\hline \multirow{3}{*}{ No } & \multicolumn{2}{|c|}{ Posisi } & \multirow{2}{*}{\multicolumn{7}{|c|}{$\begin{array}{c}\text { Eror dalam arah sumbu- } \boldsymbol{x} \text { selama tujuh kali percobaan } \\
\qquad(\mathrm{mm}), \text { ketelitian } \pm 0,5 \mathrm{~mm} \\
\text { Percobaan ke: }\end{array}$}} \\
\hline & \multirow{2}{*}{ Awal } & \multirow{2}{*}{ Tujuan } & & & & & & & \\
\hline & & & 1 & 2 & 3 & 4 & 5 & 6 & 7 \\
\hline 1 & \multirow{3}{*}{$\begin{array}{l}\text { Load / } \\
\text { Unload }\end{array}$} & Lantai-1 & 1 & -1 & 0 & 0 & -1 & -1 & 1 \\
\hline 2 & & Lantai-2 & 0 & 1 & -1 & $x$ & -2 & -1 & $x$ \\
\hline 3 & & Lantai-3 & -1 & -1 & 1 & -2 & -1 & -1 & -2 \\
\hline 4 & Lantai-1 & \multirow{3}{*}{$\mathrm{CNC}$} & -1 & -1 & 0 & -1 & $x$ & $x$ & $x$ \\
\hline 5 & Lantai-2 & & 0 & $x$ & -1 & 1 & $x$ & 1 & -1 \\
\hline 6 & Lantai-3 & & 1 & -1 & $x$ & $x$ & $x$ & 1 & $x$ \\
\hline 7 & \multirow{3}{*}{$\mathrm{CNC}$} & Lantai-1 & -2 & 0 & 1 & -1 & -1 & -1 & -1 \\
\hline 8 & & Lantai-2 & 0 & 2 & -1 & -1 & -1 & $x$ & 2 \\
\hline 9 & & Lantai-3 & -1 & -1 & 2 & 2 & $x$ & $x$ & -1 \\
\hline 10 & Lantai-1 & \multirow{3}{*}{$\begin{array}{l}\text { Load / } \\
\text { Unload }\end{array}$} & 0 & 1 & -1 & -1 & 2 & $x$ & $x$ \\
\hline 11 & Lantai-2 & & -1 & -1 & $x$ & $x$ & -1 & 1 & -1 \\
\hline 12 & Lantai-3 & & -1 & -1 & 1 & 1 & $x$ & $x$ & 1 \\
\hline
\end{tabular}

Catatan : $\times$ adalah benda kerja jatuh

\begin{tabular}{|c|c|c|c|c|c|c|c|c|c|}
\hline \multirow{3}{*}{ No } & \multicolumn{2}{|c|}{ Posisi } & \multirow{2}{*}{\multicolumn{7}{|c|}{$\begin{array}{l}\text { Eror dalam arah sumbu-z selama tujuh kali percobaan } \\
\qquad(\mathrm{mm}), \text { ketelitian } \pm 0,5 \mathrm{~mm} \\
\text { Percobaan ke: }\end{array}$}} \\
\hline & \multirow{2}{*}{ Awal } & \multirow{2}{*}{ Tujuan } & & & & & & & \\
\hline & & & 1 & 2 & 3 & 4 & 5 & 6 & 7 \\
\hline 1 & \multirow{3}{*}{$\begin{array}{l}\text { Load / } \\
\text { Unload }\end{array}$} & Lantai-1 & 2 & 0 & 2 & 2 & -2 & -2 & -1 \\
\hline 2 & & Lantai-2 & -1 & 0 & -1 & $x$ & 1 & -1 & $x$ \\
\hline 3 & & Lantai-3 & 1 & 1 & 2 & -1 & -1 & 2 & -1 \\
\hline 4 & Lantai-1 & \multirow{3}{*}{$\mathrm{CNC}$} & 2 & -1 & -2 & 2 & $x$ & $x$ & $x$ \\
\hline 5 & Lantai-2 & & -1 & $x$ & 2 & 1 & $x$ & -1 & 2 \\
\hline 6 & Lantai-3 & & 0 & 2 & $x$ & $x$ & $x$ & 2 & $x$ \\
\hline 7 & \multirow{3}{*}{$\mathrm{CNC}$} & Lantai-1 & 1 & 2 & -1 & -2 & -2 & -1 & 1 \\
\hline 8 & & Lantai-2 & -2 & 0 & -1 & -2 & 2 & $x$ & -1 \\
\hline 9 & & Lantai-3 & -1 & 1 & 1 & 1 & $x$ & $x$ & -1 \\
\hline 10 & Lantai-1 & \multirow{3}{*}{$\begin{array}{l}\text { Load / } \\
\text { Unload }\end{array}$} & 1 & 2 & 1 & 1 & -1 & $x$ & $x$ \\
\hline 11 & Lantai-2 & & -1 & 0 & $x$ & $x$ & -2 & -1 & -2 \\
\hline 12 & Lantai-3 & & 0 & -1 & -1 & -1 & $x$ & $x$ & 1 \\
\hline
\end{tabular}

\section{Kesimpulan}

Berdasarkan pengujian yang telah dilakukan, maka dapat disimpulkan:

1. Peneliti telah merancang model stacker crane yang terdiri bottom frame, mast dan carriage, menggunakan

sebuah mikrokontroler, tiga stepper motor, tiga lead screw dan modul komunikasi via bluetooth.

2. Model stacker crane dapat beroperasi mengambil dan mengantarkan benda ke tujuan sesuai perintah yang diberikan oleh user melalui android.

3. Hasil pengujian menunjukkan terdapat kesalahan peletakan barang oleh stacker crane sebesar $0,33 \mathrm{~mm}$ ke arah sumbu- $x$ positif, $1 \mathrm{~mm}$ pada gerakan ke arah sumbu- $x$ negatif, ke atas pada sumbu-y positif $1,33 \mathrm{~mm}$, ke bawah pada arah sumbu- $y$ negatif $1,2 \mathrm{~mm}$.
Penelitian ini tentunya akan dikembangkan lebih lanjut dengan perancangan konstruksi yang mempertimbangkan struktur mekanik, untuk menjamin ketelitian dan ketepatan. Pemilihan material dan model pallet dapat menggunakan bahan yang lebih kaku, misalnya menggunakan logam paduan aluminium. Selain itu operasi dan kendali stacker crane menggunakan aplikasi yang dapat diatur ke beberapa tempat tujuan.

\section{Daftar Pustaka}

Setiawan, A., Wangsaputra, R., Martawirya, Y.Y. \& Halim, A.H. (2019). An ObjectOriented Modeling Approach for Production Scheduling on CNC-Machines in Flexible Manufacturing System to Maximize Cutting Tool Utilization. Journal of Advanced Manufacturing Systems, 18(2), 293-310. 
Hilmanto, M., Setiawan, A., \& Sitepu, T. E. N. (2018). Model Penjadwalan Flexible Manufacturing System dengan Memperhatikan Sistem Penanganan Material. Jurnal Telematika - Institut Teknologi Harapan Bangsa, (IESC).

Elroy, M., \& Setiawan, A. (2019). Perancangan Model Real Time - Shop Floor Control System Untuk Flexible Manufacturing System. Tugas Akhir, Teknik Industri Institut Teknologi Harapan Bangsa.

Utomo, A.P., Setiawan, A., \& Gunarto, F.Z. (2018). Perancangan Sistem Pengisian dan Pembacaan Data Informasi Benda Kerja pada Flexible Manufacturing System dengan Memanfaatkan Teknologi Radio Frequency Identification. Jurnal Telematika Institut Teknologi Harapan Bangsa, 13(12).

Febrian, R., \& Setiawan, A. (2019). Pembuatan Model Automatic Pallet Changer Mesin Computer Numerical Control Menggunakan Mikrokontroler. Tugas Akhir, Teknik Industri - Institut Teknologi Harapan Bangsa.

Bawono, A.N., \& Setiawan, A. (2019). Model Automated Guided Vehicle Untuk Pengangkutan barang Otomatis Menggunakan Robot Line Follower dan
Robotic ARM. Tugas Akhir, Teknik Industri Institut Teknologi Harapan Bangsa.

Andika, J. (2013). Pengontrolan Robot Berbasis Arduino Menggunakan Android. Tugas Akhir, Universitas Mercu Buana, Jakarta.

Hadisantoso, F. S., \& Tamsir, A. (2018). Perancangan Sistem Penyimpanan dan Pengambilan Barang Otomatis Menggunakan Arduino Berbasis Web Database. Jurnal Elektra, 3(1), 25-36.

Fatoni, A., \& Rendra, D. B. (2014). Perancangan Prototype Sistem kendali Lampu Menggunakan Handphone Android Berbasis Arduino. Jurnal Prosisko, 1, 23-29.

Pratama, A. D. (2017). Kontroler Lengan Robot Menggunakan Motor Servo dan Motor Stepper Dengan Masukan 3- Axis. Tugas Akhir, Universitas Sanata Dharma, Yogyakarta.

Sitepu, T.E.N., \& Setiawan, A. (2016). Penjadwalan Job Dua Stages dan penentuan Perkakas potong pada Flexible Manufacturing System Menggunakan Metode Genetic Algorithm. Jurnal Telematika Institut Teknologi Harapan Bangsa, 12(2), 123-132. 